\title{
Acquired resistance to irradiation or docetaxel is not associated with cross-resistance to cisplatin in prostate cancer cell lines
}

\author{
Lukas Donix ${ }^{1,2} \cdot$ Holger H. H. Erb ${ }^{1}$. Claudia Peitzsch ${ }^{2,3} \cdot$ Anna Dubrovska $^{2,3,4,5} \cdot$ Manuel Pfeifer $^{6} \cdot$ Christian Thomas $^{1,2}$. \\ Susanne Fuessel ${ }^{1,3} \cdot$ Kati Erdmann $^{1,2,5}$
}

Received: 27 October 2021 / Accepted: 31 December 2021 / Published online: 12 January 2022

(c) The Author(s) 2022

\begin{abstract}
Purpose Platinum chemotherapy can be considered to treat metastatic castration-resistant prostate cancer (mCRPC) with features of neuroendocrine differentiation. However, platinum compounds are generally only applied after the failure of multiple prior-line treatment options. This study investigated whether acquired resistance against ionizing radiation or docetaxel chemotherapy - two commonly applied treatment modalities in prostate cancer-influences the cisplatin (CDDP) tolerance in mCRPC cell line models.

Methods Age-matched parental as well as radio- or docetaxel-resistant DU145 and PC-3 cell lines were treated with CDDP and their sensitivity was assessed by measurements of growth rates, viability, apoptosis, metabolic activity and colony formation ability.

Results The data suggest that docetaxel resistance does not influence CDDP tolerance in all tested docetaxel-resistant cell lines. Radio-resistance was associated with sensitization to CDDP in PC-3, but not in DU145 cells. In general, DU145 cells tolerated higher CDDP concentrations than PC-3 cells regardless of acquired resistances. Furthermore, non-age-matched treatment-naïve PC-3 cells exhibited significantly different CDDP tolerances.

Conclusion Like patients, different mCRPC cell lines exhibit significant variability regarding CDDP tolerance. The presented in vitro data suggest that previous radiation treatment may be associated with a moderate sensitization to CDDP in an isogenic and age-matched setting. Therefore, previous radiotherapy or docetaxel chemotherapy might be no contraindication against initiation of platinum chemotherapy in selected mCRPC patients.
\end{abstract}

Keywords Cisplatin $\cdot$ Docetaxel $\cdot \mathrm{mCRPC} \cdot \mathrm{NEPC} \cdot$ Prostate cancer $\cdot$ Radiotherapy

\section{Introduction}

In men, prostate cancer $(\mathrm{PCa})$ has the second-highest incidence among all cancers in the developed world and was responsible for $6.8 \%$ of cancer-related mortality worldwide in 2020 (Sung et al. 2021). Furthermore, the Global

Kati Erdmann

kati.erdmann@uniklinikum-dresden.de

1 Department of Urology, Faculty of Medicine, Technische Universität Dresden, Fetscherstr. 74, 01307 Dresden, Germany

2 National Center for Tumor Diseases (NCT), Dresden, Germany: German Cancer Research Center (DKFZ), Heidelberg, Germany; Faculty of Medicine and University Hospital Carl Gustav Carus, Technische Universität Dresden, Dresden, Germany; Helmholtz-Zentrum Dresden-Rossendorf (HZDR), Dresden, Germany
Cancer Observatory projects worldwide PCa cases to increase by $60 \%$ in the next two decades driven by population growth and rising life expectancy (WHO 2021). For locally confined $\mathrm{PCa}$, radical prostatectomy and external beam radiotherapy are the treatment options with curative intent. While radical prostatectomy is generally the more

3 National Center for Radiation Research in Oncology (OncoRay), Faculty of Medicine, Technische Universität Dresden, Dresden, Germany

4 Helmholtz-Zentrum Dresden-Rossendorf, Institute of Radiooncology - OncoRay, Dresden, Germany

5 German Cancer Consortium (DKTK), Partner Site Dresden, Dresden and German Cancer Research Center (DKFZ), Heidelberg, Germany

6 Institute of Legal Medicine, Faculty of Medicine, Technische Universität Dresden, Dresden, Germany 
prevalent method, the average utilization of radiotherapy ranges from $11.8 \%$ in Germany to $38.4 \%$ in the US (Hager et al. 2015). Metastatic castration-sensitive PCa can be treated by androgen deprivation combined with docetaxel (DTX) chemotherapy, the CYP17 inhibitor abiraterone or newer generation antiandrogens (Cornford et al. 2021). Depending on the prior treatment regimen and genetic features, androgen-signaling modulators such as abiraterone and antiandrogens, taxane-based chemotherapy with DTX or cabazitaxel as well as poly(ADP ribose)polymerase (PARP) inhibitors constitute the current clinical standard of care for metastatic castration-resistant PCa (mCRPC) (Cornford et al. 2021). Consecutive therapy modalities after progression on taxanes, androgen-signaling-targeted therapies and PARP inhibitors are scarce and hardly standardized.

Neuroendocrine (NE) prostate cancer (NEPC) is a variation of $\mathrm{PCa}$ that can be treated with platinum chemotherapy. Therapies consisting of either cisplatin (CDDP) or carboplatin in combination with taxanes or etoposide achieve a median overall survival of usually less than a year in this terminal disease (Aparicio et al. 2013; Corn et al. 2019; Culine et al. 2007; Flechon et al. 2011; Papandreou et al. 2002; Steineck et al. 2002). NEPC is characterized by a diminished response to androgen ablation and commonly exhibits characteristics of small cell histology (predominant or partial) and expression of NE markers such as neuron-specific enolase (NSE), chromogranin A (CGA) and synaptophysin (SYP) (Aparicio et al. 2013; Corn et al. 2019; Culine et al. 2007; Flechon et al. 2011; Papandreou et al. 2002; Steineck et al. 2002). While NEPCs are rare at primary PCa diagnosis $(<1 \%$ of cases), prospective biopsies of mCRPC tissue revealed NE features in $11.2 \%$ of the samples (Abida et al. 2019) and autopsies revealed their presence in $10-20 \%$ of men dying with mCRPC (Shah et al. 2004; Tanaka et al. 2001; Turbat-Herrera et al. 1988).

Besides NEPC, other applications of platinum chemotherapy may emerge in the future. Several groups have published case reports and retrospective studies describing promising responses to platinum chemotherapy in mCRPC with homologous recombination repair (HRR) deficiency (Cheng et al. 2016; Pomerantz et al. 2017; Schmid et al. 2020; Zafeiriou et al. 2019). With $10 \%$ of mCRPC-derived tumor specimens having mutations in the HRR gene BRCA2 (Abida et al. 2017), HRR deficiency is common in mCRPC. Platinum-based therapies induce intra- and interstrand DNA crosslinks and have repeatedly shown increased efficacy in HRR-deficient cancer entities including mCRPC (Cheng et al. 2016; Pennington et al. 2014). Furthermore, an interventional phase I study (NCT03275857) currently evaluates CDDP for enzalutamide-refractory mCRPC (NIH 2021). However, as of now, the application of platinum chemotherapy is primarily limited to NEPC treatment.

Refined therapy regimens with a growing variety of efficient androgen-signaling modulators prolongate survival in mCRPC patients and thus, NEPC may become a common late-stage challenge. Additionally, novel applications for platinum chemotherapy besides NEPC may emerge and in summary, the importance of platinum-based therapies for mCRPC management might grow. Because the subset of mCRPC patients initiated on platinum chemotherapy is small and intertumoral genetic diversity overlaps with considerable variety of prior treatment histories, it is challenging for retrospective studies to dissect the influence of prior treatment histories on platinum efficacy.

To address this problem, we investigated putative effects of prior treatment with either ionizing radiation (IR) or DTX on CDDP tolerance in DU145 and PC-3 cells. DU145 and PC-3 are two widely used models for mCRPC. PC-3 cells express the NE markers NSE (van Bokhoven et al. 2003) and CGA (Tai et al. 2011). When xenografted into mice, PC-3 cells exhibit a small cell histology that can be described as reminiscent of NEPC (Tai et al. 2011). DU145 cells, on the other hand, lack NE features (van Bokhoven et al. 2003). Radio-resistant (RR) (Cojoc et al. 2015; Peitzsch et al. 2016) and DTX-resistant (DTXR) (Puhr et al. 2012) DU145 and PC-3 cells as well as their isogenic and age-matched parental cell lines were treated with CDDP in vitro. Their CDDP sensitivity was assessed by measurements of growth rates, viability, apoptosis, metabolic activity and colony formation ability.

\section{Materials and methods}

\section{Cell lines and culture conditions}

Dr. Martin Puhr and Prof. Dr. Zoran Culig provided DU145 ${ }^{\Delta}$ DTXR, PC $3^{\Delta}$ DTXR and their parental cell lines (Puhr et al. 2012) and Dr. Claudia Peitzsch and Prof. Dr. Anna Dubrovska provided DU145 ${ }^{\#}$ RR, PC- $3^{\#}$ RR and their parental cell lines (Peitzsch et al. 2016). Cell lines are listed in Table 1. The cells were cultured under standard conditions $\left(37{ }^{\circ} \mathrm{C}\right.$, humidified atmosphere with $5 \% \mathrm{CO}_{2}$ ) in RPMI1640 medium (Thermo Fisher Scientific, Waltham, MA, USA) supplemented with $10 \%$ fetal bovine serum (Thermo Fisher Scientific). DTXR cells continuously received $10 \mathrm{nM}$ DTX (Merck Millipore, Darmstadt, Germany) to maintain the selection pressure. Cryo-conserved RR cell lines were previously shown to maintain their RR properties for three months without additional conditioning (Peitzsch et al. 2016). Accordingly, RR cells were used for a maximum of six weeks in this study. All cell lines were authenticated by Short Tandem Repeat (STR) analysis (Table S1). For STR 
Table 1 Cell lines used in this study

\begin{tabular}{lll}
\hline Parental control cell lines & Treatment-resistant sublines & Resistance established by \\
\hline DU145 ${ }^{\Delta}$ CTRL \& & DU145 $5^{\Delta}$ DTXR \& & Dose escalation $^{\mathrm{a}}$ \\
PC-3 ${ }^{\Delta}$ CTRL & PC-3 ${ }^{\Delta}$ DTXR & (Puhr et al. 2012) \\
DU145 $5^{\#}$ CTRL \& & DU145 RR \& & Fractionated irradiation \\
PC-3 ${ }^{\#}$ CTRL & PC-3 $3^{\#}$ RR & (Cojoc et al. 2015) \\
\hline
\end{tabular}

${ }^{a}$ DTX tolerance of cells is shown in Fig. S1

${ }^{\mathrm{b}}$ Radio-resistance of cells was shown in the cited publication analysis, cell line DNA was amplified using PowerPlex 18D System (Promega, Mannheim, Germany) according to manufacturer's instructions. Capillary electrophoresis was then performed with ABI 3500 Genetic Analyzer (Thermo Fisher Scientific) and analyzed by GeneMapper ID-X software version 1.4 (Thermo Fisher Scientific). All cells were regularly tested for mycoplasma using the Mycoalert ${ }^{\mathrm{TM}}$ Mycoplasma Detection kit (Lonza, Basel, Switzerland) according to the manufacturer's instructions.

\section{Dose-response to chemotherapy}

Tolerances for CDDP and DTX were determined by treatment with serial dilutions followed by various readouts. In 96-well plates, 800 DU145 or 2,000 PC-3 cells were seeded per well. For DTX treatment, the cells were cultured to $~ 50 \%$ confluence and then treated with $0.1 \mathrm{nM}-10 \mu \mathrm{M}$ DTX for $24 \mathrm{~h}$. Next, the treatment solution was removed, fresh cell culture medium was added and $24 \mathrm{~h}$ later metabolic activity and viability were measured by WST-1 assay (Roche, Mannheim, Germany) according to the manufacturer's instructions. WST-1 is metabolized to formazan by the mitochondrial succinate-tetrazolium-reductase system. Thus, the readout is positively proportional to the degree of energy generation via oxidative phosphorylation in metabolically active cells. The formazan absorption was measured at $450 \mathrm{~nm}$ with a reference measurement at $620 \mathrm{~nm}$ using a Berthold Mithras LB940 microplate reader (Berthold Technologies, Bad Wildheim, Germany).

For CDDP, the cells were treated with $0.01-1.0 \mu \mathrm{g} / \mathrm{mL}$ CDDP $24 \mathrm{~h}$ after seeding. Cell growth in CDDP presence was studied by measurement of cell confluence in $6 \mathrm{~h}$-intervals over the course of one week using the IncuCyte S3 Live-Cell Analysis System (Sartorius, Göttingen, Germany). The confluence measurement at $144 \mathrm{~h}$ (6 days after seeding) was used to calculate the inhibition curves. Subsequently, the WST-1 assay was performed. Next, adherent cells were fixed with methanol and stained with an aqueous solution of $0.1 \%$ crystal violet (Merck Millipore) for $10 \mathrm{~min}$. After thorough washing with water, stained adherent cells were dissolved by adding $100 \mu \mathrm{L}$ of $0.1 \mathrm{M}$ sodium citrate in $50 \%$ ethanol per well and incubating for $30 \mathrm{~min}$ on a shaker. Crystal violet absorption was measured at $590 \mathrm{~nm}$ using a Berthold Mithras LB940 microplate reader (Berthold Technologies).

\section{Apoptosis and colony forming assays}

Cells were seeded in 6-well plates $(15,000$ per well for all DU145 lines, 50,000 for PC-3 RR and 30,000 for all other PC-3 lines), cultured to $\sim 50 \%$ confluence and then treated with $0.01-1.0 \mu \mathrm{g} / \mathrm{mL}$ CDDP or 5.6-560 nM DTX for $24 \mathrm{~h}$. The treatment was removed and $24 \mathrm{~h}$ later, non-adherent and adherent cells were harvested with an aqueous solution containing $0.05 \%$ trypsin/EDTA (Thermo Fisher Scientific). The cell suspensions were centrifuged, the pellets resuspended in ice-cold PBS and thereafter kept on ice. Viable cells were counted using the Muse ${ }^{\circledR}$ Count \& Viability kit on a Muse ${ }^{\circledR}$ Cell Analyzer flow cytometer (Luminex Corporation, Austin, TX, USA) according to the manufacturer's instructions. For measurement of apoptosis based on pan-caspase activity, $4 \times 10^{4}$ viable cells were analyzed using the Muse ${ }^{\circledR}$ Multi Caspase kit (Luminex Corporation) on the Muse ${ }^{\circledR}$ Cell Analyzer according to the manufacturer's instructions. For colony formation assays, technical triplicates of 100 (for all DU145 cells) or 200 (for all PC-3 cells) viable cells per well were seeded into 6-well plates. At day 8-12 of culture, bright field images of non-stained colonies were taken with the IncuCyte S3 Live-Cell Analysis System and the colonies were counted from these images. The field of view covered $80 \%$ of the total surface of the culture wells. Only colonies with $>20$ cells were considered. Colonies were then fixed with methanol, stained with an aqueous solution of $0.1 \%$ crystal violet and recounted to validate the image-based counting method.

\section{Statistics}

Curve-fitting, calculation of half-maximal inhibitory concentrations $\left(\mathrm{IC}_{50}\right)$, statistical tests and plotting were performed using GraphPad Prism 9 (GraphPad Software, San Diego, CA, USA). For the cell growth tracked by live-cell imaging, non-linear ' $\log$ (agonist) vs. response' regression with variable slope was used for curve-fitting. The lower plateau was constrained to be $\geq 0$ and the upper plateau was constrained to be $\leq 100$. When evaluating the response to 
chemotherapy treatment based on cell confluence at $144 \mathrm{~h}$, on the WST-1 assay or the crystal violet assay, the data were first normalized to the untreated control and then log-transformed. Non-linear ' $\log$ (inhibitor) vs. response' regression with variable slope was used for curve-fitting and to calculate the $\mathrm{IC}_{50}$ values. Due to data normalization, the upper plateaus of the inhibition curves were constrained to equal 1. The lower plateaus were constrained to be $\geq 0$.

For colony formation assays, the numbers of colonies in treated groups were normalized to the number of colonies in the untreated group and $x$-fold numbers of cells were plotted. The colony count reduction in response to treatment was modeled by fitting negative exponential growth curves onto the data. The concentration $\beta$ at which colony formation was reduced by $50 \%$ was inferred from the curve and is noted as $\beta_{1 / 2}$ on graphs. Due to previous data normalization, the curves were constrained to cross the $y$-axis at $y=1$.

All experiments conducted in this study were performed with at least three (up to six) biological replicates and data are depicted as mean \pm standard deviation (SD) if not otherwise stated. All statistical tests were done without the assumption of equal variance. Non-paired $t$-tests with Welch's correction were performed to test for the statistical significance of differences between two groups. For comparisons between multiple groups, Brown-Forsythe and Welch ANOVA combined with Tukey's test for multiple comparisons were used. $P$ values $<0.05$ were considered statistically significant.

\section{Results}

\section{Validation of cell line authenticity and treatment resistance}

The identity of all cell lines was confirmed by STR analysis. The observed repeat-length of tetra- and pentanucleotide repeat markers (Urquhart et al. 1994) included in the authentication panel largely matched the expected repeat-length for these markers. DU145 cells exhibited minor deviations of observed versus expected repeat-length more often than PC-3 cells (Table S1). For example, DU $145^{\Delta}$ CTRL and DU $145^{\Delta}$ DTXR exhibited minor deviations from the STR profile published by ATCC in 7/15 and 11/15 markers, respectively. The instability of STR markers observed in DU145 cell lines may be attributed to the documented DNA mismatch repair (MMR) deficiency in these cells (Boyer et al. 1995; Chen et al. 2001; Lu et al. 2013).

Radio-resistance in DU145 $5^{\#} \mathrm{RR}$ and PC- $3^{\#} \mathrm{RR}$ was previously demonstrated (Peitzsch et al. 2016). To confirm DTX resistance of DTXR cell lines, the cells were treated with serial dilutions of DTX. DTXR cells exhibited a significantly increased DTX tolerance based on the WST-1 assay $\left(\mathrm{IC}_{50}\right.$ of $5.9 \mathrm{nM}$ in DU145 ${ }^{\Delta}$ CTRL vs $388 \mathrm{nM}$ in DU $145^{\Delta}$ DTXR and $8.2 \mathrm{nM}$ in PC- $3^{\Delta}$ CTRL vs $305 \mathrm{nM}$ in PC- $3^{\Delta}$ DTXR) (Fig. S1a). Colony formation assays (Fig. S1b) confirmed these results.

\section{CDDP treatment of radio-resistant cells}

DU145 ${ }^{\#}$ RR and PC- $3^{\#}$ RR cell lines as well as their nonresistant parental controls were treated with a serial dilution of CDDP and subjected to functional analysis. Cell confluence was tracked over one week in the IncuCyte S3 LiveCell Analysis System (Fig. S2a). Cell growth under CDDP pressure was comparable between CTRL and RR cells at concentrations lower than $0.1 \mu \mathrm{g} / \mathrm{mL}$ CDDP in DU145 and at concentrations lower than $0.05 \mu \mathrm{g} / \mathrm{mL}$ CDDP in PC- 3 cell lines (Fig. S2a). Differences emerged at higher concentrations. DU145 ${ }^{\#}$ RR cells grew at $0.5 \mu \mathrm{g} / \mathrm{mL}$ CDDP, while the corresponding treatment-naïve DU145 ${ }^{\#}$ CTRL cells did not proliferate at this concentration. In contrast, PC- $3^{\#}$ CTRL cells tolerated CDDP concentrations from 0.1 to $0.25 \mu \mathrm{g} /$ $\mathrm{mL}$ better than PC-3 ${ }^{\#}$ RR cells (Fig. S2a). Inhibition curves calculated from the cell confluence at $144 \mathrm{~h}$ (Fig. 1a) suggest that DU145 ${ }^{\#}$ RR cells are more resistant and PC- $3^{\#}$ RR are more sensitive to CDDP than their corresponding parental control cell lines.

Consecutive to cell growth tracking, cellular viability was measured by WST-1 assay (Fig. 1 b). $\mathrm{IC}_{50}$ values calculated from the resulting inhibition curves equaled $0.19,0.22$, 0.12 and $0.07 \mu \mathrm{g} / \mathrm{mL}$ CDDP in DU145 ${ }^{\#}$ CTRL, DU145 ${ }^{\#} \mathrm{RR}$, PC- $3^{\#}$ CTRL and PC- $3^{\#}$ RR cells, respectively. Based on the WST-1 assay, no significant differences in CDDP tolerance were observed between RR cells and their parental controls (Fig. 1b).

Subsequently, crystal violet assays were performed (Fig. 1c) determining the total adherent (viable) cell mass. Crystal violet assays revealed no difference between DU145 CTRL and DU145 ${ }^{\#}$ RR cells. However, the results implied PC- $3^{\#}$ RR to be more sensitive to CDDP than PC- $3^{\#}$ CTRL (Fig. 1c).

DU145 ${ }^{\#}$ CTRL and DU145 ${ }^{\#}$ RR exhibited nearly identical colony formation efficiency after CDDP treatment (Fig. 1d). Colony formation efficiency was slightly higher in PC- $3^{\#}$ CTRL vs PC- $3^{\#}$ RR cells (Fig. $1 \mathrm{~d}, P<0.05$ at 0.1 and $0.2 \mu \mathrm{g}$ / $\mathrm{mL}$ CDDP), which is in line with results obtained from other readouts as described above.

CDDP treatment led to an induction of apoptosis only in DU145 ${ }^{\#}$ CTRL cells (Fig. S2b). Induction of apoptosis by CDDP was not observed in DU145 ${ }^{\#}$ RR, PC- $3^{\#}$ CTRL or PC- $3^{\#}$ RR. However, untreated RR cell lines had a significantly higher basal pan-caspase activity than their parental controls (Fig. S2b). 


\section{DU145 \# $\square$ CTRL $\square R R$}

PC-3 \# $\square$ CTRL $\square R R$

a
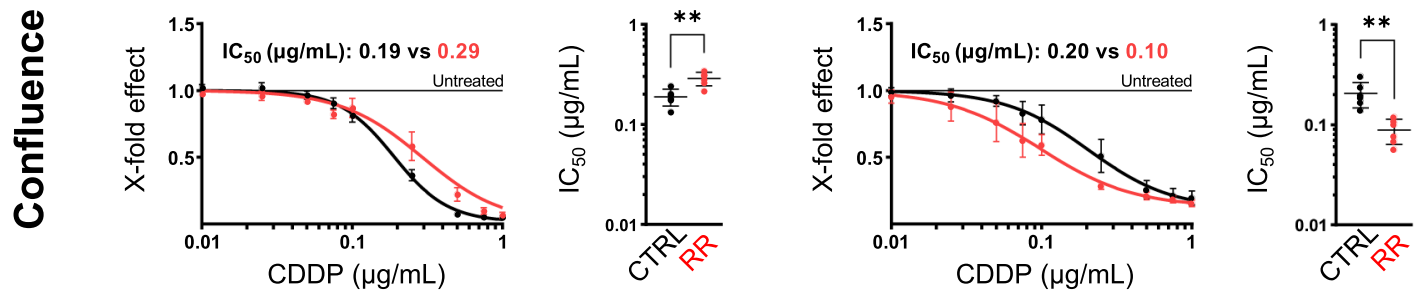

b
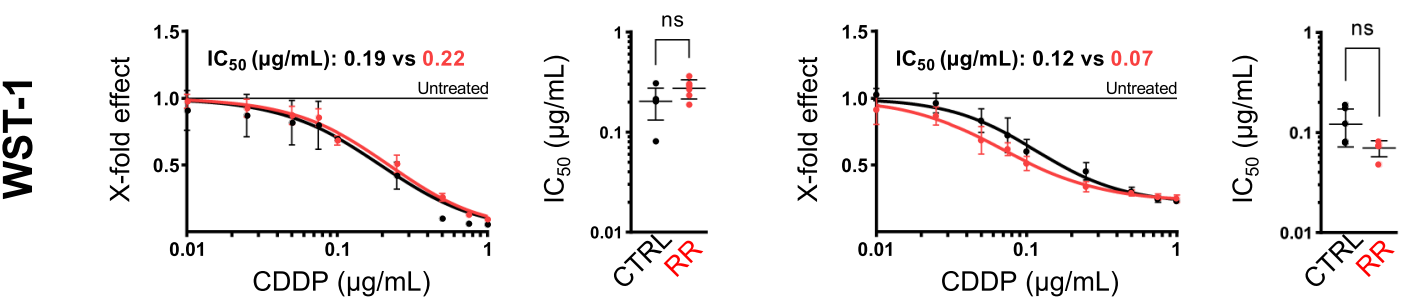

C
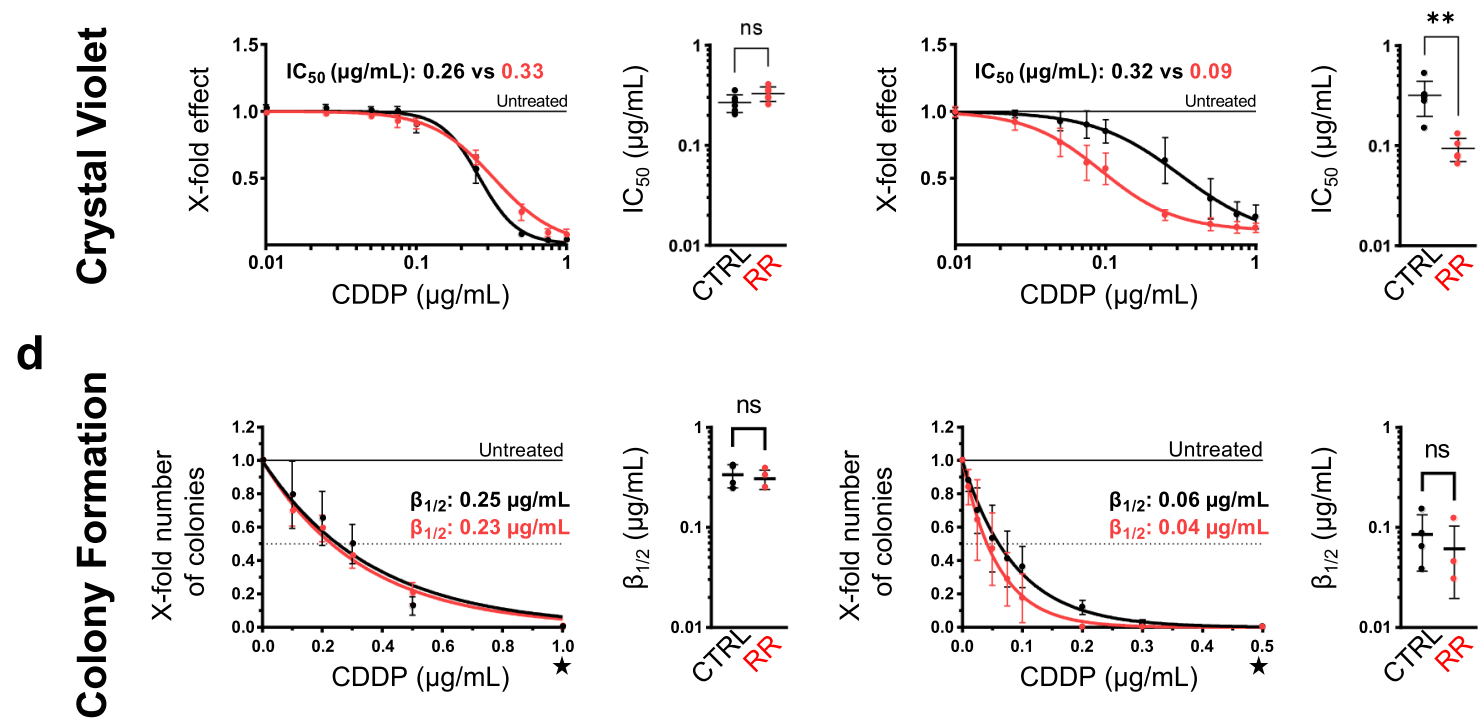

Fig. 1 Evaluation of CDDP tolerance in radio-resistant DU145 and PC-3 cells. Radio-resistant cells and their parental controls were treated with CDDP. a Cell confluence at $144 \mathrm{~h}$ : The $x$-fold confluence of treated cells normalized to untreated cells at $144 \mathrm{~h}$ after seeding is plotted. b WST-1 assay: The $x$-fold metabolic activity of treated cells normalized to untreated cells is plotted. c Crystal violet assay: The $x$-fold viability of treated cells normalized to untreated cells is plotted. a-c $\mathrm{IC}_{50}$ values were calculated from the resulting inhibition curves and are noted in the graphs, whereas $\mathrm{IC}_{50}$ values calculated from individual experiments are depicted in the adjacent graphs. d Colony formation assay: The $x$-fold number of colonies of treated cells normalized to untreated cells is plotted. The concentrations $\beta_{1 / 2}$, at which colony formation abilities were reduced by $50 \%$, were inferred from the fitted curves and are noted in the graphs. The $\star$ symbol highlights the different $x$-axis scaling for DU145 $5^{\#}$ and PC- $3^{\#}$ cells. All data are presented as mean \pm SD and experiments were repeated for $N \geq 3$ times. Non-paired $t$-tests with Welch's correction were performed to test for statistical significance of the differences between RR cells and parental controls or between treated and untreated cells. $n s$ not significant, $* P<0.05, * * P<0.01$

\section{CDDP treatment of docetaxel-resistant cells}

Analogous to RR cells, DTXR cells and their parental controls were treated with CDDP and growth was studied by continuous imaging. Comparing DTXR cell lines to their age-matched parental controls, cell growth was identical along the entire CDDP serial dilution (Fig. S2c). DU145 ${ }^{\Delta}$ CTRL and DU $145^{\Delta}$ DTXR cells grew in the presence of up to $0.25 \mu \mathrm{g} / \mathrm{mL}$ CDDP, whereas PC- $3^{\Delta}$ CTRL and PC- $3^{\Delta}$ DTXR cells proliferated in the presence of up to $0.1 \mu \mathrm{g} / \mathrm{mL}$ CDDP (Fig. S2c). IC 50 values calculated from the inhibition curves based on the cell confluence at $144 \mathrm{~h}$ (Fig. 2a) 
suggested no differences between DTXR cells and their corresponding parental control cell lines.

$\mathrm{IC}_{50}$ values based on the WST-1 assay (Fig. 2b) were 0.18, 0.20, 0.06 and $0.06 \mu \mathrm{g} / \mathrm{mL}$ CDDP in DU145 ${ }^{\Delta} \mathrm{CTRL}$, DU $145^{\Delta}$ DTXR, PC $-3^{\Delta}$ CTRL and PC- $3^{\Delta}$ DTXR cells, respectively. Based on the WST-1 assay, no significant differences in CDDP tolerance were observed between DTXR cells and their parental controls (Fig. 2b). Likewise, consecutive crystal violet assays exhibited no difference between DTXR cells and their corresponding parental control cell lines (Fig. 2c).
DU145 ${ }^{\Delta} \square$ CTRL $\square$ DTXR

a

b
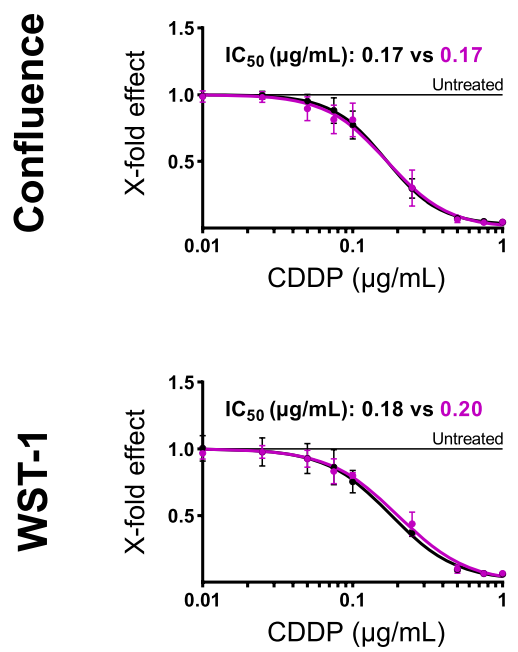

C
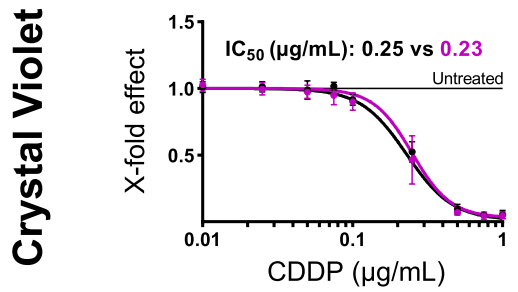

d

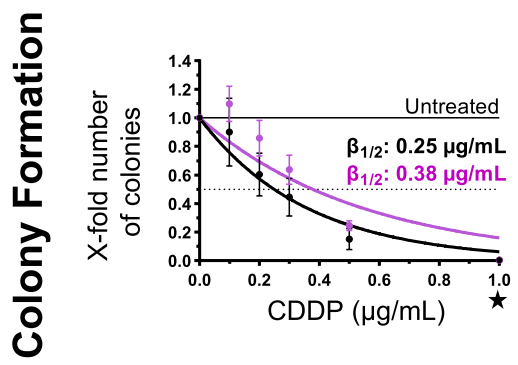

\section{PC-3 $\Delta$ QCTRL $\square$ DTXR}
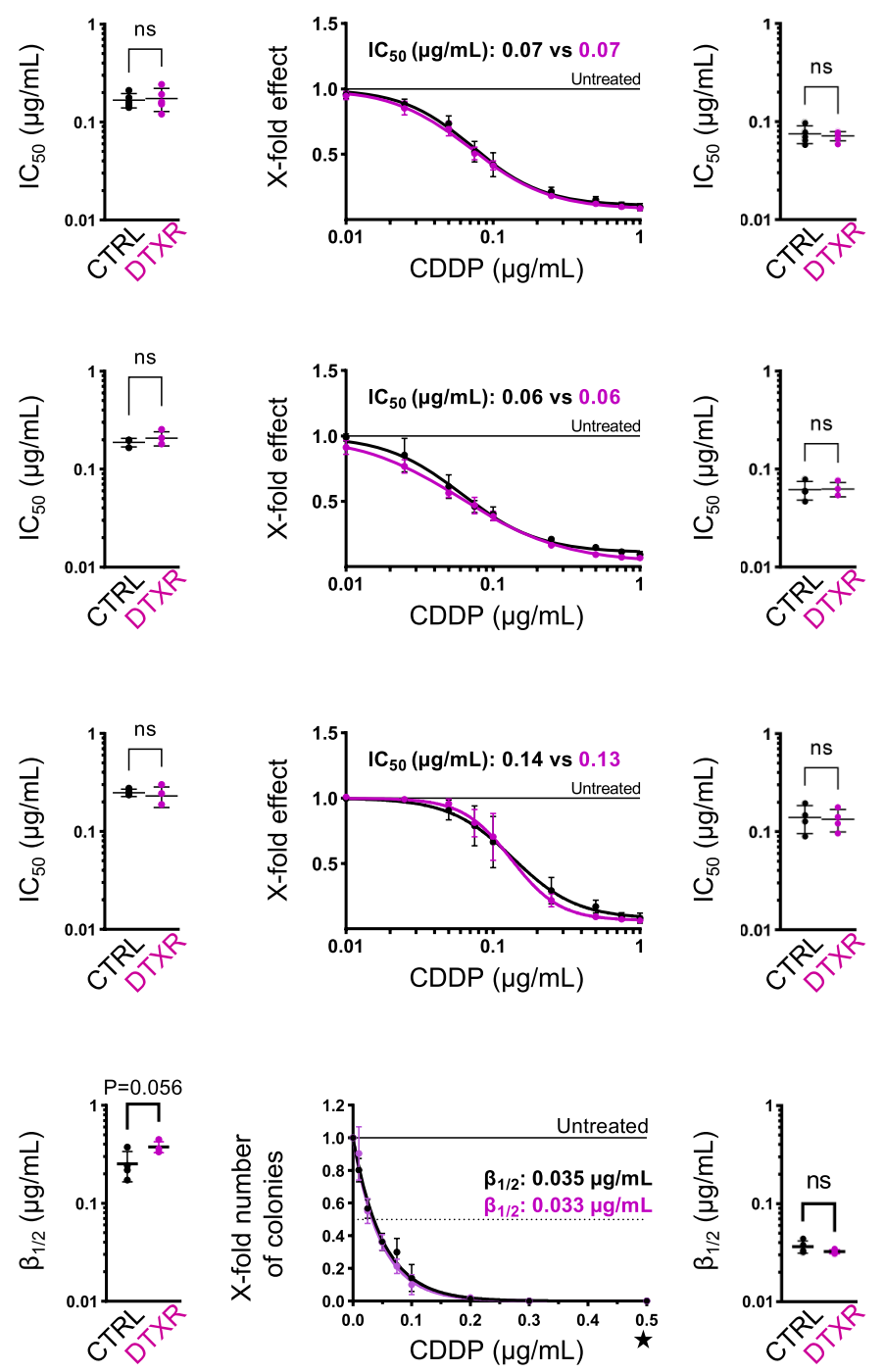

Fig. 2 Evaluation of CDDP tolerance in docetaxel-resistant DU145 and PC-3 cells. Docetaxel-resistant cells and their parental controls were treated with CDDP. a Cell confluence at $144 \mathrm{~h}$ : The $x$-fold confluence of treated cells normalized to untreated cells at $144 \mathrm{~h}$ after seeding is plotted. b WST-1 assay: The $x$-fold metabolic activity of treated cells normalized to untreated cells is plotted. c Crystal violet assay: The $x$-fold viability of treated cells normalized to untreated cells is plotted. a-c $\mathrm{IC}_{50}$ values were calculated from the resulting inhibition curves and are noted in the graphs, whereas $\mathrm{IC}_{50}$ values calculated from individual experiments are depicted in the adjacent graphs. d Colony formation assay: The $x$-fold number of colonies of treated cells normalized to untreated cells is plotted. The concentrations $\beta_{1 / 2}$, at which colony formation abilities were reduced by $50 \%$, were inferred from the fitted curves and are noted in the graphs. The $\star$ symbol highlights the different $x$-axis scaling for DU $145^{\Delta}$ and PC- $3^{\Delta}$ cells. All data are presented as mean \pm SD and experiments were repeated for $N \geq 3$ times. Non-paired $t$-tests with Welch's correction were performed to test for statistical significance of the differences between DTXR cells and parental controls or between treated and untreated cells. $n s$ not significant, $* P<0.05$, $* * P<0.01$ 
DU $145^{\Delta}$ DTXR cells exhibited a slightly higher colony formation efficiency compared to DU $145^{\Delta}$ CTRL cells at low concentrations of CDDP between 0.1 and $0.3 \mu \mathrm{g} / \mathrm{mL}$ (Fig. $2 \mathrm{~d}, P<0.05$ at $0.2 \mu \mathrm{g} / \mathrm{mL}$ CDDP). In PC- ${ }^{\Delta}$ CTRL and PC- $3^{\Delta}$ DTXR cells, CDDP inhibited colony formation efficiency to identical degrees along the entire range of tested concentrations (Fig. 2d).

Treatment with CDDP induced pan-caspase activity in all cell lines to comparable degrees, but revealed no difference between DTXR and non-resistant cells (Fig. S2d).

\section{CDDP tolerance among treatment-naïve control cells}

Based on colony formation assays, DU145 cells tolerated higher concentrations of CDDP than PC- 3 cells. In contrast to PC-3 cells, DU145 cells maintained residual levels of colony forming ability after treatment with up to $0.5 \mu \mathrm{g} /$ $\mathrm{mL}$ CDDP (Fig. 3a). Based on cell confluence at $144 \mathrm{~h}$, on WST-1 assay and on crystal violet assay the higher tolerance of DU145 CTRL cells was observed only vs PC- $3^{\Delta}$ CTRL, but not vs PC- $3^{\#}$ CTRL cells (Fig. 3b, bottom row). CDDP tolerance in DU145 ${ }^{\Delta}$ CTRL compared to DU145 ${ }^{\#}$ CTRL cells was nearly identical (Fig. 3a, b).

Cell growth under CDDP pressure suggested that $\mathrm{PC}-3^{\Delta}$ CTRL are more sensitive to CDDP than PC- $3^{\#}$ CTRL cells. PC- $3^{\#}$ CTRL cells proliferated at up to $0.25 \mu \mathrm{g} / \mathrm{mL}$ CDDP, while in PC- $3^{\Delta}$ CTRL growth was abolished at this concentration (compare Fig. S2a, c). Inhibition curves and $\mathrm{IC}_{50}$ values based on the cell confluence at $144 \mathrm{~h}$ and crystal violet assays also indicated higher CDDP sensitivity of PC- $3^{\Delta}$ CTRL than PC-3 ${ }^{\#}$ CTRL cells (Fig. $3 b$ ).

\section{Discussion}

Platinum compounds are generally only applied after the failure of multiple prior-line treatment options. Therefore, we investigated whether acquired resistance against IR or DTX, which are two commonly applied treatment modalities in PCa, influences CDDP tolerance in the $\mathrm{mCRPC}$ cell line models PC-3 and DU145. In current clinical practice, platinum chemotherapy is primarily used to treat NEPC patients. The PC-3 cell line does exhibit NE features (Tai et al. 2011; van Bokhoven et al. 2003) and can therefore be considered as a model system for a patient that might be selected for platinum chemotherapy. DU145 cells, on the other hand, do not exhibit NE features (van Bokhoven et al. 2003).

The DTXR cells used in this study exhibited strongly increased DTX tolerance, as shown previously (Puhr et al. 2012) and confirmed within this study. Among others, Puhr et al. demonstrated that the DTX-resistant phenotype in these cells was associated with epithelial to mesenchymal transition (EMT)-like changes in cell morphology. This notion was supported by gene expression studies that confirmed upregulation of mesenchymal and downregulation of epithelial markers (Hanrahan et al. 2017; Puhr et al. 2012). EMT has been linked to increased CDDP tolerance in various cancer entities (Ashrafizadeh et al. 2020). In accordance, we confirmed the downregulation of the epithelial cell marker E-cadherin and also the differential expression of genes not directly linked to EMT such as ABCB1—one of the well-studied effector proteins of multi-drug and DTX resistance-in both DTXR cell lines (unpublished). Taken together, DTXR cells exhibit numerous differences at the transcriptomic and proteomic levels compared to their age-matched parental control cells. Despite that, our dose-response experiments unanimously showed no sign of difference in CDDP tolerance between DTXR and control cell lines. This suggests that the cellular adaptations associated with DTX resistance, including EMT, do not affect CDDP tolerance in DU145 and PC-3 human metastatic PCa cell lines.

Previous treatment with IR yielded contradicting results for CDDP tolerance in PC- $3^{\#}$ CTRL vs PC- $3^{\#}$ RR on one hand and DU145 ${ }^{\#}$ CTRL vs DU145 ${ }^{\#}$ RR on the other. DU145 ${ }^{\#}$ CTRL and DU145 ${ }^{\#}$ RR generally exhibited comparable CDDP tolerance. However, the cell growth under CDDP pressure and cell confluence at $144 \mathrm{~h}$ indicated DU145 ${ }^{\#}$ RR cells to be slightly more tolerant than DU145 CTRL cells towards CDDP. In contrast, $\mathrm{PC}-3^{\#} \mathrm{RR}$ cells were more sensitive to CDDP treatment than PC- $3^{\#}$ CTRL cells based on cell growth, cell confluence at $144 \mathrm{~h}$, crystal violet assays and colony formation assays.

RR cells were obtained by IR treatment, which causes large numbers of DNA lesions randomly distributed across the genome, not all of which are repaired with conservation of the original sequence. The consequence of this is that $R R$ and CTRL cell line pairs are not entirely isogenic, which has been shown for DU145 ${ }^{\#}$ RR (Seifert et al. 2019). Although DNA lesions caused by IR are randomly distributed, it is possible that $\mathrm{PC}-3^{\#} \mathrm{RR}$ acquired mutations rendering them less capable of tolerating CDDP than non-radiated PC- $3^{\#}$ CTRL.

IR-induced DNA lesions include single-strand breaks, double-strand breaks (DSBs), DNA inter-strand crosslinks, and single base modifications (Mladenov et al. 2013). DSBs are considered to be the main drivers of IR cytotoxicity and are repaired through either HRR or variants of non-homologous end joining (Mladenov et al. 2013). Reactive oxygen species generated by IR lead to base modifications, of which 8-oxo-guanine (8-oxoG) is particularly common (David et al. 2007). 8-oxoG lesions are primarily repaired through base excision repair (David et al. 2007). However, transcriptioncoupled repair (Le Page et al. 2000), nucleotide excision repair (Scott et al. 1999) and MMR (Brierley and Martin 
a

Colony Formation Assay
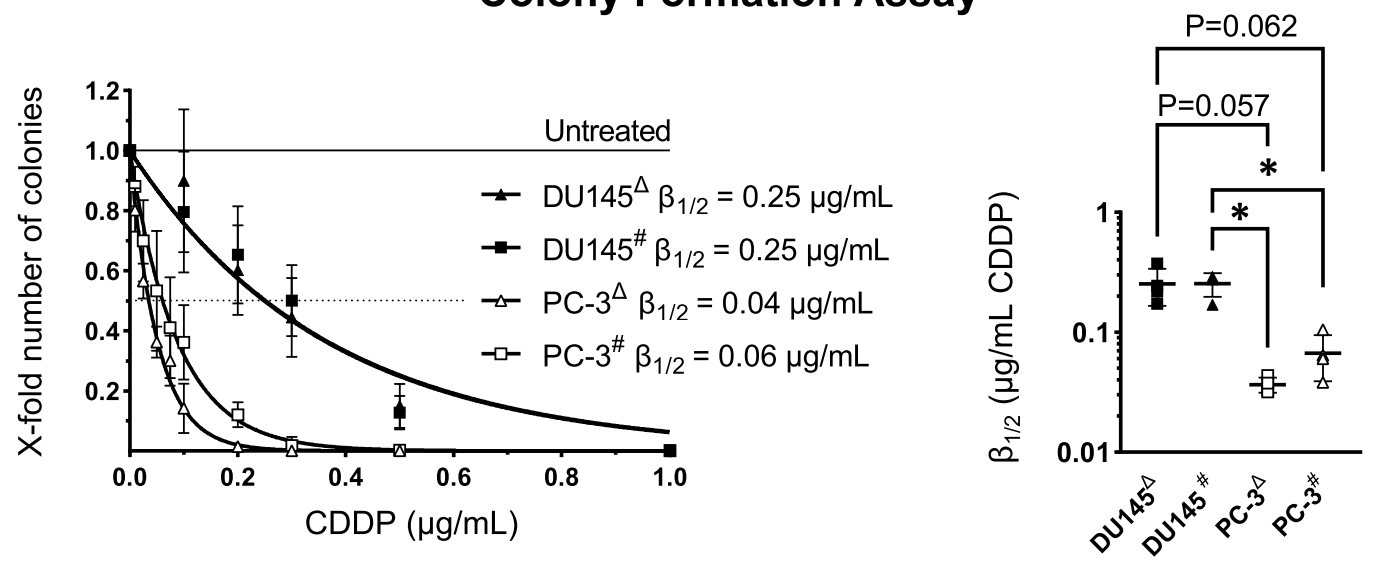

b

\section{Confluence}
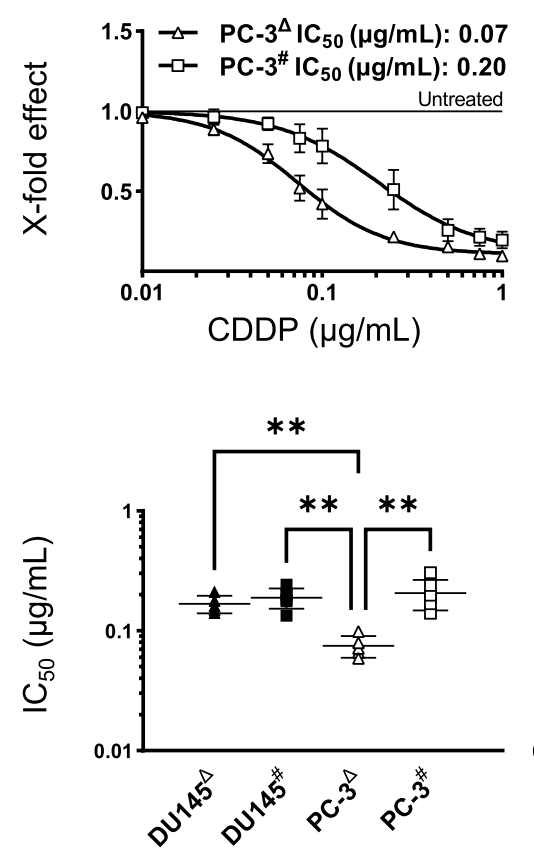

WST-1 Assay
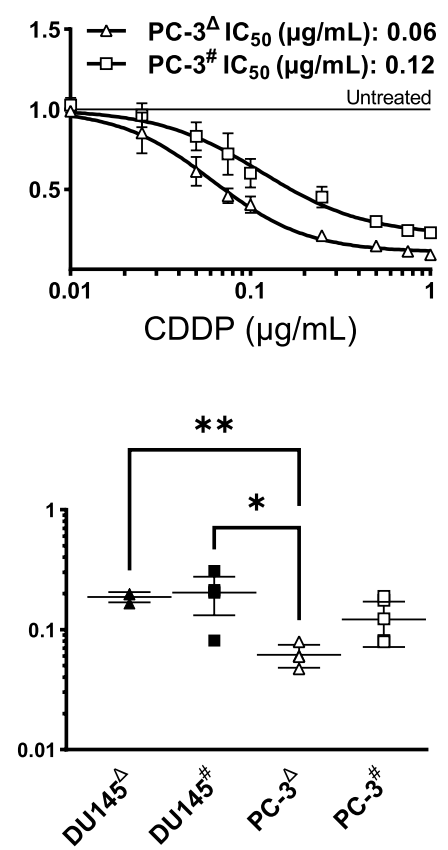

Crystal Violet Assay
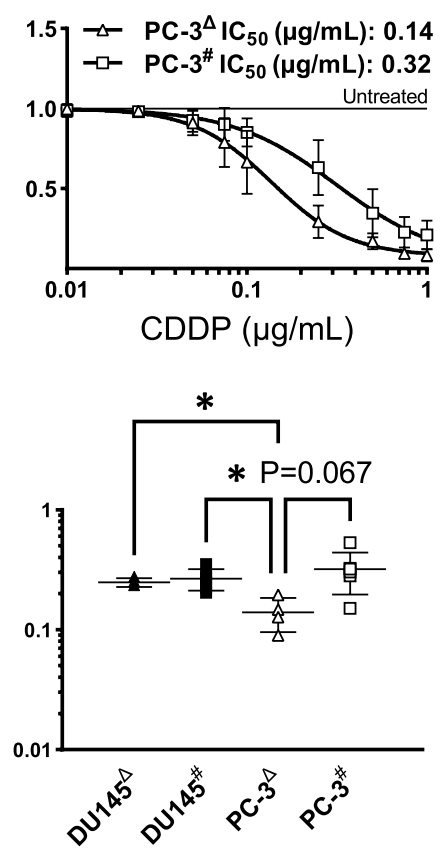

Fig. 3 Comparison of CDDP tolerance in control cells. For this figure, the data that were shown in Figs. 1 and 2 were reorganized to allow for an easier comparison of CDDP tolerance between nonisogenic (PC-3 vs DU145) and non-age-matched (PC-3 ${ }^{\#}$ CTRL vs PC $-3^{\Delta}$ CTRL) treatment-naïve control cells. a Results of the colony formation assays in all control cell lines are depicted. Adjacent, $\beta_{1 / 2}$ values calculated from individual experiments $(N \geq 3)$ and the results of an ANOVA with multiple comparisons are shown. b Doseresponse curves of PC- $3^{\Delta}$ CTRL and PC- $3^{\#}$ CTRL cells based on the cell confluence at $144 \mathrm{~h}$, the WST-1 assay and the crystal violet assay

2013) have been implicated as backup and auxiliary repair systems.

HRR and nucleotide excision repair are essential for repairing DNA lesions caused by treatment with platinum compounds such as CDDP (Kelland 2007; Pennington et al. are shown. DU145 ${ }^{\#}$ CTRL and DU145 ${ }^{\triangle}$ CTRL are omitted to allow for a better visual comparison of PC- $3^{\Delta}$ CTRL and PC- $3^{\#}$ CTRL cells. Beneath, $\mathrm{IC}_{50}$ values calculated from individual experiments and the results of an ANOVA with multiple comparisons including DU145 ${ }^{\Delta}$ CTRL and DU145 ${ }^{\#}$ CTRL cells are shown. Significant test results $(P<0.05)$ are annotated with asterisks and near significant test results $(P<0.1)$ are annotated with their $P$ values. All data are presented as mean \pm SD and experiments were repeated for $N \geq 3$ times. ns not significant, $* P<0.05$, $* * P<0.01$

2014). As elaborated, the diverse types of DNA damage caused by IR treatment require activity of the entire range of DNA-repair pathways. IR treatment may therefore increase the activity of e.g. the HRR pathway, which may in turn enhance a cell's ability to tolerate CDDP. 
However, increased activity of the MMR pathwaywhich may be a consequence of 8-oxoG mismatches caused by IR-would have a well-established negative effect on CDDP tolerance (Aebi et al. 1996; Fink et al. 1996). Mechanistically, the MMR system recognizes platinum-induced DNA lesions but fails to repair them, fostering apoptosis due to stalled DNA repair complexes (Bassett et al. 2002; Fink et al. 1996; Kelland 2007; Sawant et al. 2015). Therefore, when the activity of the MMR pathway is increased, CDDP tolerance is decreased. Conversely, deficiency for MMR pathway members including MSH2, MSH3, MSH6 and MLH1 can increase platinum resistance (Fink et al. 1996; Goodspeed et al. 2019; Sawant et al. 2015). The detailed role of MMR in the repair of IR-induced 8-oxoG lesions is debated. While some studies suggest that the MMR system can recognize and successfully repair 8-oxoG mismatches (Brierley and Martin 2013), others propose a 'futile repair' mechanism similar to what has been described for platinuminduced lesions (Larson et al. 2003). Studies agree, however, that MMR proteins recognize and interact with 8-oxoG mismatches.

Following this line of thought, increased activity of the MMR system in consequence of the IR treatment could provide a possible explanation for the increased sensitivity to CDDP observed in PC- $3^{\#}$ RR vs PC- $3^{\#}$ CTRL cells. This effect would not materialize in DU145 cells as these cells are MMR-deficient due to a fatal truncating mutation in the MMR gene MLH1 (Boyer et al. 1995; Chen et al. 2001; Lu et al. 2013). Indeed, unlike PC- $3^{\#}$ RR, DU145 ${ }^{\#}$ RR cells did not exhibit increased sensitivity to CDDP relative to their control cells and even tolerated slightly higher CDDP concentrations based on cell growth and cell confluence at $144 \mathrm{~h}$.

The presented experiments point out additional observations apart from the comparisons of resistant vs agematched non-resistant cells. In colony formation assays, treatment-naïve DU145 cells tolerated higher CDDP doses than PC-3 cells. MMR deficiency was already discussed above as a possible driver of increased CDDP tolerance in DU145 cells. Another explanation for increased CDDP tolerance in DU145 relative to PC-3 cells could be given by differences in the NE differentiation status between these two cell lines. While DU145 cells are negative for common markers of NE differentiation, PC-3 cells are positive for NSE (van Bokhoven et al. 2003) and CGA (Tai et al. 2011). Additionally, PC-3 xenografts in mice exhibited expression patterns of NSE, CGA, CK-8 and CD44 as well as histomorphologic features akin to NEPC biopsy samples (Tai et al. 2011). In patients, there is solid evidence that NEPC responds better to platinum treatment than mCRPC without NE features (Aparicio et al. 2013; Humeniuk et al. 2018; Papandreou et al. 2002).
Furthermore, we observed a significant difference in CDDP tolerance comparing the PC- $3^{\#}$ CTRL (Cojoc et al. 2015) to PC- $3^{\Delta}$ CTRL (Puhr et al. 2012) cells. Both cell lines were purchased from ATCC by their original owners and were authenticated before experimentation in this study. All cell lines were cultured in RPMI-1640 medium supplemented with $10 \%$ serum and $2 \mathrm{mM}$ L-glutamine in this study. However, in their original laboratories, PC- $3^{\#}$ CTRL received DMEM, while PC- $3^{\Delta}$ CTRL received RPMI-1640 (with $10 \%$ serum and $2 \mathrm{mM}$ L-glutamine). Naturally, PC- $3^{\#}$ CTRL and PC- $3^{\Delta}$ CTRL cells are not age-matched and in addition to different historical culture conditions, passage number effects might account for the observed experimental results.

In patients, platinum-based chemotherapies are administered to treat NEPC and recent studies have described enhanced efficacy in mCRPC with HRR deficiency (Cheng et al. 2016; Pomerantz et al. 2017; Schmid et al. 2020; Zafeiriou et al. 2019). The PARP inhibitor olaparib has recently been approved to treat HRR-deficient mCRPC. Therapies involving platinum compounds alone or in combination with PARP inhibition may be a new direction to be evaluated prospectively in this genetic subset of mCRPC patients.

Our work aimed to evaluate the influence of the treatment history on CDDP tolerance and indicates that DTX resistance is not associated with altered CDDP tolerance in mCRPC cell line models. Previous radiation treatment might sensitize cells to CDDP as suggested by comparing PC- $3^{\#}$ RR with age-matched PC- $3^{\#}$ CTRL cells. However, our data indicated significant differences in CDDP tolerance between DU145 and PC-3 cells as well as between PC- $3^{\#}$ CTRL and PC- $3^{\Delta}$ CTRL cells, putting the observed effect size of the possible radiation-associated sensitization in PC- $3^{\#} \mathrm{RR}$ cells into perspective.

In conclusion, prior radiation or DTX treatment are likely not contraindications against the application of CDDP and radiation treatment may be associated with CDDP sensitization. However, this effect may often be masked by the influence of the genetic background. Therefore, to confirm or reject the existence and clinical significance of such an effect, convincing prospective clinical studies would require detailed patient data and sufficiently large cohorts.

Supplementary Information The online version contains supplementary material available at https://doi.org/10.1007/s00432-022-03914-5.

Author contributions Conceptualization: LD and KE; methodology: $\mathrm{LD}$ and $\mathrm{KE}$; formal analysis: $\mathrm{LD}$ and $\mathrm{MP}$; investigation: $\mathrm{LD}$; resources: HE, CP, AD, CT, SF and KE; data curation: LD; writing-original draft preparation: $\mathrm{LD}$; writing - review and editing: $\mathrm{LD}, \mathrm{HE}, \mathrm{CP}, \mathrm{AD}$, MP, CT, SF and KE; visualization: LD; supervision: CT, SF and KE; 
project administration: SF and KE. All authors have read and agreed to the published version of the manuscript.

Funding Open Access funding enabled and organized by Projekt DEAL.

Availability of data and material The data presented in this study are available from the corresponding author upon reasonable request.

Code availability Not applicable.

\section{Declarations}

Conflict of interest The authors declare that they have no conflict of interest.

Ethics approval Not applicable.

Open Access This article is licensed under a Creative Commons Attribution 4.0 International License, which permits use, sharing, adaptation, distribution and reproduction in any medium or format, as long as you give appropriate credit to the original author(s) and the source, provide a link to the Creative Commons licence, and indicate if changes were made. The images or other third party material in this article are included in the article's Creative Commons licence, unless indicated otherwise in a credit line to the material. If material is not included in the article's Creative Commons licence and your intended use is not permitted by statutory regulation or exceeds the permitted use, you will need to obtain permission directly from the copyright holder. To view a copy of this licence, visit http://creativecommons.org/licenses/by/4.0/.

\section{References}

Abida W, Armenia J, Gopalan A, Brennan R, Walsh M, Barron D, Danila D, Rathkopf D, Morris M, Slovin S, McLaughlin B, Curtis K, Hyman DM, Durack JC, Solomon SB, Arcila ME, Zehir A, Syed A, Gao J, Chakravarty D, Vargas HA, Robson ME, Joseph V, Offit K, Donoghue MTA, Abeshouse AA, Kundra R, Heins ZJ, Penson AV, Harris C, Taylor BS, Ladanyi M, Mandelker D, Zhang L, Reuter VE, Kantoff PW, Solit DB, Berger MF, Sawyers CL, Schultz N, Scher HI (2017) Prospective genomic profiling of prostate cancer across disease states reveals germline and somatic alterations that may affect clinical decision making. JCO Precis Oncol. https://doi.org/10.1200/PO.17.00029

Abida W, Cyrta J, Heller G, Prandi D, Armenia J, Coleman I, Cieslik M, Benelli M, Robinson D, Van Allen EM, Sboner A, Fedrizzi T, Mosquera JM, Robinson BD, De Sarkar N, Kunju LP, Tomlins S, Wu YM, Nava Rodrigues D, Loda M, Gopalan A, Reuter VE, Pritchard CC, Mateo J, Bianchini D, Miranda S, Carreira S, Rescigno P, Filipenko J, Vinson J, Montgomery RB, Beltran H, Heath EI, Scher HI, Kantoff PW, Taplin ME, Schultz N, deBono JS, Demichelis F, Nelson PS, Rubin MA, Chinnaiyan AM, Sawyers CL (2019) Genomic correlates of clinical outcome in advanced prostate cancer. Proc Natl Acad Sci USA 116:1142811436. https://doi.org/10.1073/pnas.1902651116

Aebi S, Kurdi-Haidar B, Gordon R, Cenni B, Zheng H, Fink D, Christen RD, Boland CR, Koi M, Fishel R, Howell SB (1996) Loss of DNA mismatch repair in acquired resistance to cisplatin. Cancer Res 56:3087-3090

Aparicio AM, Harzstark AL, Corn PG, Wen S, Araujo JC, Tu SM, Pagliaro LC, Kim J, Millikan RE, Ryan C, Tannir NM, Zurita
AJ, Mathew P, Arap W, Troncoso P, Thall PF, Logothetis CJ (2013) Platinum-based chemotherapy for variant castrate-resistant prostate cancer. Clin Cancer Res 19:3621-3630. https://doi. org/10.1158/1078-0432.CCR-12-3791

Ashrafizadeh M, Zarrabi A, Hushmandi K, Kalantari M, Mohammadinejad R, Javaheri T, Sethi G (2020) Association of the epithelial-mesenchymal transition (EMT) with cisplatin resistance. Int J Mol Sci. https://doi.org/10.3390/ijms21114002

Bassett E, Vaisman A, Tropea KA, McCall CM, Masutani C, Hanaoka F, Chaney SG (2002) Frameshifts and deletions during in vitro translesion synthesis past Pt-DNA adducts by DNA polymerases beta and eta. DNA Repair (amst) 1:1003-1016. https://doi.org/10.1016/s1568-7864(02)00150-7

Boyer JC, Umar A, Risinger JI, Lipford JR, Kane M, Yin S, Barrett JC, Kolodner RD, Kunkel TA (1995) Microsatellite instability, mismatch repair deficiency, and genetic defects in human cancer cell lines. Cancer Res 55:6063-6070

Brierley DJ, Martin SA (2013) Oxidative stress and the DNA mismatch repair pathway. Antioxid Redox Signal 18:2420-2428. https://doi.org/10.1089/ars.2012.4994

Chen Y, Wang J, Fraig MM, Metcalf J, Turner WR, Bissada NK, Watson DK, Schweinfest CW (2001) Defects of DNA mismatch repair in human prostate cancer. Cancer Res 61:4112-4121

Cheng HH, Pritchard CC, Boyd T, Nelson PS, Montgomery B (2016) Biallelic inactivation of BRCA2 in platinum-sensitive metastatic castration-resistant prostate cancer. Eur Urol 69:992-995. https://doi.org/10.1016/j.eururo.2015.11.022

Cojoc M, Peitzsch C, Kurth I, Trautmann F, Kunz-Schughart LA, Telegeev GD, Stakhovsky EA, Walker JR, Simin K, Lyle S, Fuessel S, Erdmann K, Wirth MP, Krause M, Baumann M, Dubrovska A (2015) Aldehyde dehydrogenase is regulated by beta-catenin/TCF and promotes radioresistance in prostate cancer progenitor cells. Cancer Res 75:1482-1494. https://doi.org/ 10.1158/0008-5472.CAN-14-1924

Corn PG, Heath EI, Zurita A, Ramesh N, Xiao L, Sei E, Li-NingTapia E, Tu SM, Subudhi SK, Wang J, Wang X, Efstathiou E, Thompson TC, Troncoso P, Navin N, Logothetis CJ, Aparicio AM (2019) Cabazitaxel plus carboplatin for the treatment of men with metastatic castration-resistant prostate cancers: a randomised, open-label, phase 1-2 trial. Lancet Oncol 20:14321443. https://doi.org/10.1016/S1470-2045(19)30408-5

Cornford P, van den Bergh RCN, Briers E, Van den Broeck T, Cumberbatch MG, De Santis M, Fanti S, Fossati N, Gandaglia G, Gillessen S, Grivas N, Grummet J, Henry AM, der Kwast THV, Lam TB, Lardas M, Liew M, Mason MD, Moris L, Oprea-Lager DE, der Poel HGV, Rouviere O, Schoots IG, Tilki D, Wiegel T, Willemse PM, Mottet N (2021) EAU-EANM-ESTRO-ESURSIOG guidelines on prostate cancer. Part II-2020 update: treatment of relapsing and metastatic prostate cancer. Eur Urol 79:263-282. https://doi.org/10.1016/j.eururo.2020.09.046

Culine S, El Demery M, Lamy PJ, Iborra F, Avances C, Pinguet F (2007) Docetaxel and cisplatin in patients with metastatic androgen independent prostate cancer and circulating neuroendocrine markers. J Urol 178:844-848. https://doi.org/10.1016/j. juro.2007.05.044

David SS, O'Shea VL, Kundu S (2007) Base-excision repair of oxidative DNA damage. Nature 447:941-950. https://doi.org/10. 1038/nature05978

Fink D, Nebel S, Aebi S, Zheng H, Cenni B, Nehme A, Christen RD, Howell SB (1996) The role of DNA mismatch repair in platinum drug resistance. Cancer Res 56:4881-4886

Flechon A, Pouessel D, Ferlay C, Perol D, Beuzeboc P, Gravis G, Joly F, Oudard S, Deplanque G, Zanetta S, Fargeot P, Priou F, Droz JP, Culine S (2011) Phase II study of carboplatin and etoposide in patients with anaplastic progressive metastatic castration-resistant prostate cancer (mCRPC) with or without 
neuroendocrine differentiation: results of the French GenitoUrinary Tumor Group (GETUG) P01 trial. Ann Oncol 22:24762481. https://doi.org/10.1093/annonc/mdr004

Goodspeed A, Jean A, Costello JC (2019) A whole-genome CRISPR screen identifies a role of MSH2 in cisplatin-mediated cell death in muscle-invasive bladder cancer. Eur Urol 75:242-250. https:// doi.org/10.1016/j.eururo.2018.10.040

Hager B, Kraywinkel K, Keck B, Katalinic A, Meyer M, Zeissig SR, Stabenow R, Froehner M, Huber J (2015) Integrated prostate cancer centers might cause an overutilization of radiotherapy for low-risk prostate cancer: a comparison of treatment trends in the United States and Germany from 2004 to 2011. Radiother Oncol 115:90-95. https://doi.org/10.1016/j.radonc.2015.02.024

Hanrahan K, O'Neill A, Prencipe M, Bugler J, Murphy L, Fabre A, Puhr M, Culig Z, Murphy K, Watson RW (2017) The role of epithelial-mesenchymal transition drivers ZEB1 and ZEB2 in mediating docetaxel-resistant prostate cancer. Mol Oncol 11:251-265. https://doi.org/10.1002/1878-0261.12030

Humeniuk MS, Gupta RT, Healy P, McNamara M, Ramalingam S, Harrison M, George D, Zhang T, Wu Y, Armstrong AJ (2018) Platinum sensitivity in metastatic prostate cancer: does histology matter? Prostate Cancer Prostatic Dis 21:92-99. https://doi.org/ 10.1038/s41391-017-0017-6

Kelland L (2007) The resurgence of platinum-based cancer chemotherapy. Nat Rev Cancer 7:573-584. https://doi.org/10.1038/nrc2167

Larson ED, Iams K, Drummond JT (2003) Strand-specific processing of 8-oxoguanine by the human mismatch repair pathway: inefficient removal of 8-oxoguanine paired with adenine or cytosine. DNA Repair (amst) 2:1199-1210. https://doi.org/10.1016/s15687864(03)00140-x

Le Page F, Klungland A, Barnes DE, Sarasin A, Boiteux S (2000) Transcription coupled repair of 8-oxoguanine in murine cells: the ogg1 protein is required for repair in nontranscribed sequences but not in transcribed sequences. Proc Natl Acad Sci USA 97:8397-8402. https://doi.org/10.1073/pnas.140137297

Lu Y, Soong TD, Elemento O (2013) A novel approach for characterizing microsatellite instability in cancer cells. PLoS ONE 8:e63056. https://doi.org/10.1371/journal.pone.0063056

Mladenov E, Magin S, Soni A, Iliakis G (2013) DNA double-strand break repair as determinant of cellular radiosensitivity to killing and target in radiation therapy. Front Oncol 3:113. https://doi.org/ $10.3389 /$ fonc. 2013.00113

NIH (2021) "ClinicalTrials.gov." Retrieved 06/02/2021, from https:// clinicaltrials.gov/ct2/show/record/NCT03275857

Papandreou CN, Daliani DD, Thall PF, Tu SM, Wang X, Reyes A, Troncoso P, Logothetis CJ (2002) Results of a phase II study with doxorubicin, etoposide, and cisplatin in patients with fully characterized small-cell carcinoma of the prostate. J Clin Oncol 20:3072-3080. https://doi.org/10.1200/JCO.2002.12.065

Peitzsch C, Cojoc M, Hein L, Kurth I, Mabert K, Trautmann F, Klink B, Schrock E, Wirth MP, Krause M, Stakhovsky EA, Telegeev GD, Novotny V, Toma M, Muders M, Baretton GB, Frame FM, Maitland NJ, Baumann M, Dubrovska A (2016) An epigenetic reprogramming strategy to resensitize radioresistant prostate cancer cells. Cancer Res 76:2637-2651. https://doi.org/10.1158/ 0008-5472.CAN-15-2116

Pennington KP, Walsh T, Harrell MI, Lee MK, Pennil CC, Rendi MH, Thornton A, Norquist BM, Casadei S, Nord AS, Agnew KJ, Pritchard CC, Scroggins S, Garcia RL, King MC, Swisher EM (2014) Germline and somatic mutations in homologous recombination genes predict platinum response and survival in ovarian, fallopian tube, and peritoneal carcinomas. Clin Cancer Res 20:764-775. https://doi.org/10.1158/1078-0432.CCR-13-2287

Pomerantz MM, Spisak S, Jia L, Cronin AM, Csabai I, Ledet E, Sartor AO, Rainville I, O'Connor EP, Herbert ZT, Szallasi Z, Oh WK, Kantoff PW, Garber JE, Schrag D, Kibel AS, Freedman ML
(2017) The association between germline BRCA2 variants and sensitivity to platinum-based chemotherapy among men with metastatic prostate cancer. Cancer 123:3532-3539. https://doi. org/10.1002/cncr.30808

Puhr M, Hoefer J, Schafer G, Erb HH, Oh SJ, Klocker H, Heidegger I, Neuwirt H, Culig Z (2012) Epithelial-to-mesenchymal transition leads to docetaxel resistance in prostate cancer and is mediated by reduced expression of miR-200c and miR-205. Am J Pathol 181:2188-2201. https://doi.org/10.1016/j.ajpath.2012.08.011

Sawant A, Kothandapani A, Zhitkovich A, Sobol RW, Patrick SM (2015) Role of mismatch repair proteins in the processing of cisplatin interstrand cross-links. DNA Repair (amst) 35:126-136. https://doi.org/10.1016/j.dnarep.2015.10.003

Schmid S, Omlin A, Higano C, Sweeney C, Martinez Chanza N, Mehra N, Kuppen MCP, Beltran H, Conteduca V, Pivato V, de Almeida D, Cotait Maluf F, Oh WK, Tsao CK, Sartor O, Ledet E, Di Lorenzo G, Yip SM, Chi KN, Bianchini D, De Giorgi U, Hansen AR, Beer TM, Lavaud P, Morales-Barrera R, Tucci M, Castro E, Karalis K, Bergman AM, Le ML, Zurrer-Hardi U, Pezaro C, Suzuki H, Zivi A, Klingbiel D, Schar S, Gillessen S (2020) Activity of platinum-based chemotherapy in patients with advanced prostate cancer with and without DNA repair gene aberrations. JAMA Netw Open 3:e2021692. https://doi.org/10.1001/jaman etworkopen.2020.21692

Scott AD, Neishabury M, Jones DH, Reed SH, Boiteux S, Waters R (1999) Spontaneous mutation, oxidative DNA damage, and the roles of base and nucleotide excision repair in the yeast Saccharomyces cerevisiae. Yeast 15:205-218. https://doi.org/10.1002/ (SICI)1097-0061(199902)15:3\%3c205::AID-YEA361\%3e3.0. $\mathrm{CO} ; 2-1$

Seifert M, Peitzsch C, Gorodetska I, Borner C, Klink B, Dubrovska A (2019) Network-based analysis of prostate cancer cell lines reveals novel marker gene candidates associated with radioresistance and patient relapse. PLoS Comput Biol 15:e1007460. https://doi.org/ 10.1371/journal.pcbi.1007460

Shah RB, Mehra R, Chinnaiyan AM, Shen R, Ghosh D, Zhou M, Macvicar GR, Varambally S, Harwood J, Bismar TA, Kim R, Rubin MA, Pienta KJ (2004) Androgen-independent prostate cancer is a heterogeneous group of diseases: lessons from a rapid autopsy program. Cancer Res 64:9209-9216. https://doi.org/10. 1158/0008-5472.CAN-04-2442

Steineck G, Reuter V, Kelly WK, Frank R, Schwartz L, Scher HI (2002) Cytotoxic treatment of aggressive prostate tumors with or without neuroendocrine elements. Acta Oncol 41:668-674. https://doi.org/ $10.1080 / 028418602321028292$

Sung H, Ferlay J, Siegel RL, Laversanne M, Soerjomataram I, Jemal A, Bray F (2021) Global cancer statistics 2020: GLOBOCAN estimates of incidence and mortality worldwide for 36 cancers in 185 countries. CA Cancer J Clin 71:209-249. https://doi.org/10. 3322/caac. 21660

Tai S, Sun Y, Squires JM, Zhang H, Oh WK, Liang CZ, Huang J (2011) PC3 is a cell line characteristic of prostatic small cell carcinoma. Prostate 71:1668-1679. https://doi.org/10.1002/pros.21383

Tanaka M, Suzuki Y, Takaoka K, Suzuki N, Murakami S, Matsuzaki O, Shimazaki J (2001) Progression of prostate cancer to neuroendocrine cell tumor. Int J Urol 8:431-436. https://doi.org/10.1046/j. 1442-2042.2001.00347.x

Turbat-Herrera EA, Herrera GA, Gore I, Lott RL, Grizzle WE, Bonnin JM (1988) Neuroendocrine differentiation in prostatic carcinomas. A retrospective autopsy study. Arch Pathol Lab Med 112:1100-1105

Urquhart A, Kimpton CP, Downes TJ, Gill P (1994) Variation in short tandem repeat sequences-a survey of twelve microsatellite loci for use as forensic identification markers. Int J Legal Med 107:13-20. https://doi.org/10.1007/BF01247268 
van Bokhoven A, Varella-Garcia M, Korch C, Johannes WU, Smith EE, Miller HL, Nordeen SK, Miller GJ, Lucia MS (2003) Molecular characterization of human prostate carcinoma cell lines. Prostate 57:205-225. https://doi.org/10.1002/pros. 10290

WHO (2021) "Estimated number of new cases from 2020 to 2040; Prostate Cancer." Retrieved 15/02/2021, from https://gco.iarc.fr/ tomorrow/en/dataviz/bars? $m o d e=$ population $\&$ cancers $=27$

Zafeiriou Z, Bianchini D, Chandler R, Rescigno P, Yuan W, Carreira S, Barrero M, Petremolo A, Miranda S, Riisnaes R, Rodrigues DN, Gurel B, Sumanasuriya S, Paschalis A, Sharp A, Mateo J, Tunariu N, Chinnaiyan AM, Pritchard CC, Kelly K, de Bono JS (2019)
Genomic analysis of three metastatic prostate cancer patients with exceptional responses to carboplatin indicating different types of DNA repair deficiency. Eur Urol 75:184-192. https://doi.org/10. 1016/j.eururo.2018.09.048

Publisher's Note Springer Nature remains neutral with regard to jurisdictional claims in published maps and institutional affiliations. 